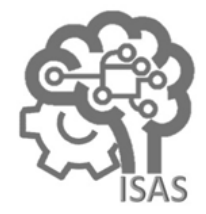

JOURNAL OF APPLIED CIVIL ENGINEERING AND INFRASTRUCTURE TECHNOLOGY (JACEIT)

Vol. 2 No. 2 (2021) 23-31

ISSN Media Elektronik: 2723-5378

\title{
Analisis Quantity Take-Off Menggunakan BIM Pada Proyek Jalan Tol "X"
}

\author{
Karina Travis ${ }^{1}$, Nunung Martina ${ }^{2}$, Safri $^{3}$ \\ 1,2,3 Jurusan Teknik Sipil, Politeknik Negeri Jakarta \\ ${ }^{1}$ karina.travis.ts17@mhsw.pnj.ac.id*, ${ }^{2}$ nunung.martina@ sipil.pnj.ac.id, ${ }^{3}$ safri@ sipil.pnj.ac.id
}

\begin{abstract}
In large and complex construction projects, Building Information Modelling (BIM) is important in the globalization of construction technology. Through the implementation of BIM, it is hoped that the " $\mathrm{X}$ " Toll Road Project can minimize errors. The problems that occurs in the field is that the QTO calculation using AutoCAD with Microsoft Excel tools in the initial estimate is less accurate so that it results in a miss calculation in the implementation, BIM is expected to be a solution to this problem. A case study was conducted to compare the quantity take-off in toll road construction on Overpass Interchange " $X$ " and Access Roads using BIM and conventional. Data analysis was obtained from carrying out quantity takeoff work using BIM and Conventional CAD as well as conducting interviews with BIM experts. Based on the research conducted, there are differences in the calculation of the take-off quantity between BIM and conventional, the percentage difference in the calculation obtained is the difference in earthworks $\pm 4,375 \%$, structural excavation difference $\pm 1,7 \%$, pavement difference $\pm 4.4 \%$, structural concrete difference $\pm 0.1 \%$, and other work $0 \%$ difference. BIM can streamline more actual volume, but it takes a long time for beginners to get accurate. BIM is influenced by the level of modeling detail, if the modeling is not modeled properly, it will give wrong volume calculation results. Compared to conventional methods, using $\mathrm{BIM}$ at the beginning of planning is very effective in preventing re-design as well as inefficient designs and miss calculations.
\end{abstract}

Keywords: BIM, conventional CAD, quantity take-off

\begin{abstract}
Abstrak
Pada proyek konstruksi besar dan kompleks, BIM (Building Information Modelling) merupakan hal penting dalam globalisasi teknologi konstruksi. Melalui penerapan BIM diharapkan pada Proyek Jalan Tol "X" dapat meminimalisir kesalahan. Masalah yang terjadi dilapangan terdapat perhitungan QTO menggunakan AutoCAD dengan alat bantu Microsoft Excel dalam estimasi awal kurang akurat sehingga menghasilkan miss kalkulasi pada pelaksanaan, BIM diharapkan dapat menjadi solusi untuk masalah ini. Dilakukan studi kasus untuk mengetahui perbandingan quantity take-off pada konstruksi jalan tol pada Overpass Interchange "X" dan Jalan Akses menggunakan BIM dan konvensional. Data analisis diperoleh dari melakukan pekerjaan quantity take-off dengan berbasis BIM dan CAD Konvensional serta melakukan wawancara kepada pakar BIM. Berdasarkan penelitian yang dilakukan terdapat perbedaan perhitungan quantity take-off antara BIM dan manual menggunakan CAD konvensional, Persentase perbedaan perhitungan yang didapatkan yaitu pada pekerjaan tanah selisih $\pm 4,375 \%$, galian struktur selisih $\pm 1,7 \%$, perkerasan selisih $\pm 4,4 \%$, struktur beton selisih $\pm 0,1 \%$, dan pekerjaan lain-lain selisih $0 \%$. BIM dapat mengefisienkan volume lebih aktual, namun membutuhkan waktu yang cukup lama untuk pemula dalam mendapatkan keakuratan. BIM dipengaruhi oleh tingkat ke-detailan pemodelan, jika pemodelan tidak dimodelkan dengan benar maka akan memberikan hasil perhitungan volume yang salah. Menggunakan BIM pada awal perencanaan sangat efektif dalam mencegah terjadinya re-desain serta desain yang tidak efisien dan miss kalkulasi.
\end{abstract}

Kata kunci: BIM, CAD konvensional, quantity take-off

Diterima Redaksi : 09-09-2021 | Selesai Revisi : 03-11-2021 | Diterbitkan Online : 01-12-2021

\section{Pendahuluan}

Quantity Surveying pada Proyek Jalan Tol "X" melakukan perhitungan QTO secara manual dengan menggunakan Autocad dan alat bantu Microsoft Excel dalam estimasi awal, menyebabkan belum terintegrasinya antara drawing-quantity-schedule-cost yang mengakibatkan terjadinya miss kalkulasi.
Quantity Take Off (QTO) diaplikasikan hampir di semua fase proyek konstruksi, oleh karena itu pekerjaan QTO harus dilakukan secara akurat dan konsisten [1]. Pemodelan desain yang berubah-ubah sangat mempengaruhi biaya dan SDM yang tidak efisien, serta dapat mempengaruhi volume pekerjaan yang dikemas dalam BoQ dan mengakibatkan 
kurangnya daya saing serta kelayakan harga keunggulan serta kendala dari software Autodesk Civil penawaran. Dampak kesalahan dalam quantitiy 3D dan Autodesk Revit, sebagai salah satu tools BIM surveying berdampak signifikan pada biaya proyek agar dapat melakukan keakurasian dan mempermudah [2][3]. Beberapa faktor yang menyebabkan kurangnya analisis quantity take-off.

keakuratan perhitungan QTO berbasis CAD konvensional yaitu kesalahan dalam pemindahan data

\section{Metode Penelitian}

antar file, resiko perhitungan ganda dan elemen yang Metode yang digunakan dalam penelitian ini adalah hilang, gambar 2D mengandung banyak kesalahan yang metode kuantitatif. Lokasi peneltian ini dilakukan di menyebabkan masalah lebih lanjut [4]. Dengan Proyek Pembangunan Jalan Tol "X". Penelitian ini mengimplementasikan BIM merupakan salah satu cara dilakukan untuk membandingkan perhitungan quantity untuk mendukung pertumbuhan infrastruktur dinegara take off menggunakan berbasis BIM dan CAD ini karena dapat meminimalisir kesalahan dalam proyek konvesional serta melakukan wawancara untuk konstruksi [5][6]. Pada proyek Jalan Tol "X" ini menemukan kendala dalam penggunaan BIM. merupakan jenis pekerjaan konstruksi jalan dan Berdasarkan kajian pustaka diperoleh kerangka jembatan yang wajib untuk menerapkan BIM hal ini diagram alir yang digunakan dalam penelitian ini pada sesuai dengan Surat Edaran No. 11/SE/Db/2021 tentang Gambar 1.

Penerapan Building Information Modelling Pada Perencanaan Teknis, Konstruksi Dan Pemeliharaan Jalan Dan Jembatan Di Direktorat Jenderal Bina Marga [7].

Menggunakan aplikasi konvensional membutuhkan waktu lebih lama karena aplikasi ini tidak dapat saling terintegrasi. Dibandingkan dengan penggunaan BIM, hal ini akan mempengaruhi biaya dan SDM yang dibutuhkan untuk menggunakan aplikasi dalam perencanaan proyek. BIM mendorong pertukaran model 3D antar disiplin ilmu yang berbeda, sehingga proses pertukaran informasi menjadi lebih efisien selama proses suatu konstruksi [8][9]. Implementasi BIM quantitiy take off memungkinkan integrasi antara model 3D dengan semua pihak yang terlibat dalam proses konstruksi dengan manfaat berupa perhitungan volume dan biaya yang sebelumnya dapat diketahui pada tahap perencanaan [10][11].

Hasil dari menggunakan software BIM akan memiliki output yang lebih akurat dan lebih detail dari pada menghitung QTO menggunakan metode sebelumnya. BIM merupakan perubahan paradigma menggantikan CAD konvensional [12][13]. Akan tetapi BIM juga memiliki beberapa potensi tantangan seperti resistensi terhadap perubahan budaya, adaptasi alur kerja yang ada untuk program berorientasi lean, pelatihan staf, pemahaman tanggung jawab, dan kurangnya staf yang berkualitas [14][15]. Beberapa hambatan lain yaitu kompleksitas perangkat lunak adalah salah satu kelemahan menggunakan BIM untuk QTO [16].

Software BIM yang digunakan pada penelitian ini adalah Autodesk Civil 3D 2021 dan Autodesk Revit 2021, kedua software ini dapat melakukan perhitungan quantity take-off secara cepat dan akurat [17].

Tujuan dari penelitian ini untuk menguraikan faktorfaktor yang terjadi pada permasalahan dari analisis quantity take-off secara manual dengan menggunakan aplikasi 2D tradisional Autocad dan alat bantu Microsoft Excel dalam pengestimasian awal pada Proyek Pembangunan Jalan Tol " $\mathrm{X}$ " dan mengetahui

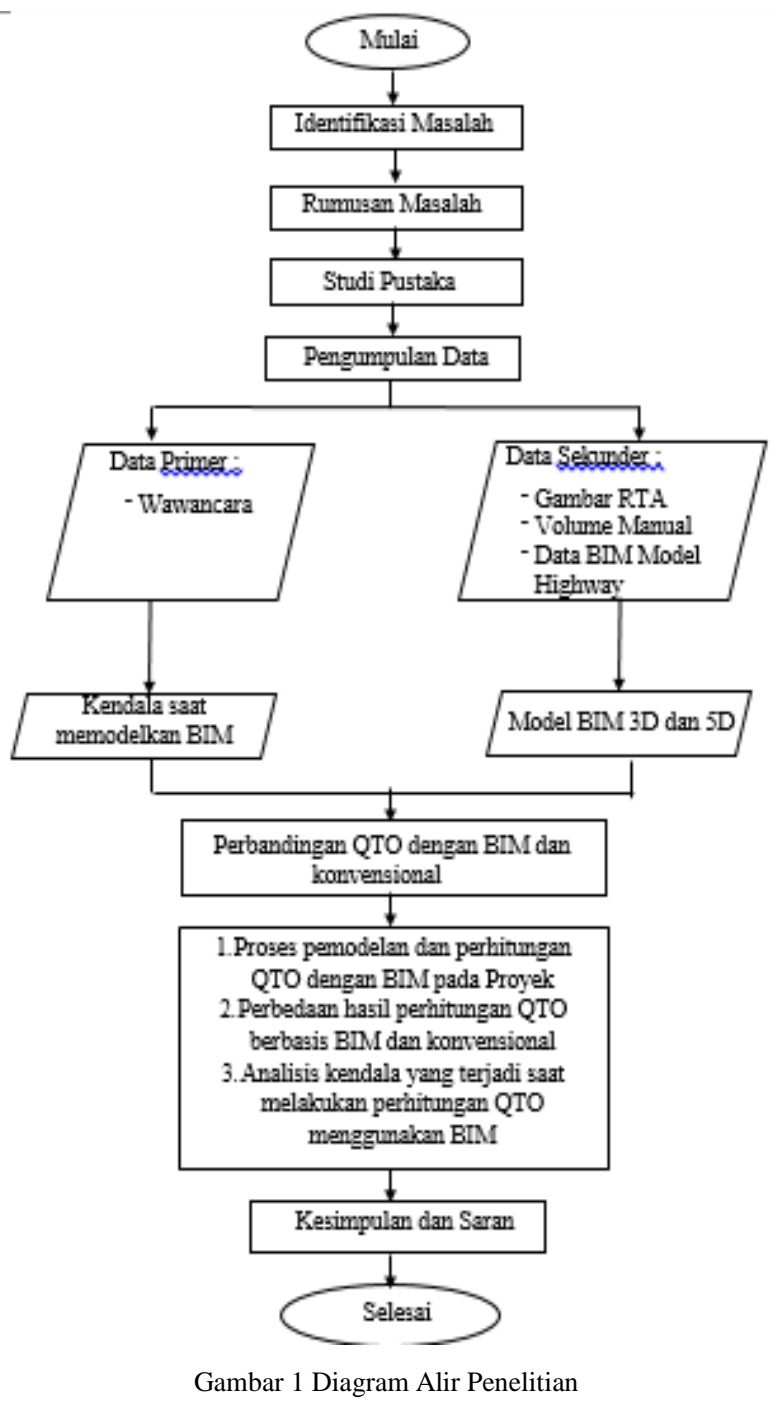

2.1. Metode Pengumpulan Data dan Analisis Data

Data primer yang digunakan adalah hasil wawancara untuk mengetahui kendala dari penerapan BIM. Data sekunder yang digunakan yaitu Gambar RTA, data perhitungan volume secara manual dan data BIM Model highway. Input pada BIM yaitu memerlukan 
gambar RTA dan data BIM Model highway yang berasal dari proyek, dalam format PDF maupun DWG. Proses pada BIM yaitu dengan memodelkan jalan akses dan struktur overpass. Yang terakhir yaitu output model yang dihasilkan oleh BIM akan merepresentasikan bentuk digital dari jalan akses dan struktur overpass. BIM yang digunakan pada penelitian ini telah memiliki fitur untuk merekapitulasi hasil quantity take off. Hasil tersebut berupa total volume dan juga luas permukaan nya. Selanjutnya dihitung persentase perbedaan hasil perhitungan QTO berbasis CAD konvensional dan BIM.

\subsection{Pemodelan 3D Jalan Akses/At Grade}

Untuk pemodelan pekerjaan civilwork pada jalan akses/at grade akan dilakukan dengan perangkat lunak Autodesk Civil 3D. Output dari pemodelan ini adalah file .DWG yang berisi seluruh data dari pemodelan yang sudah dikerjakan. Untuk merencanakan highways menggunakan Autodesk Civil3D terdapat tahapantahapan sebagai berikut:

1. Membuat alignment horizontal at grade seperti yang terlihat pada Gambar 2.

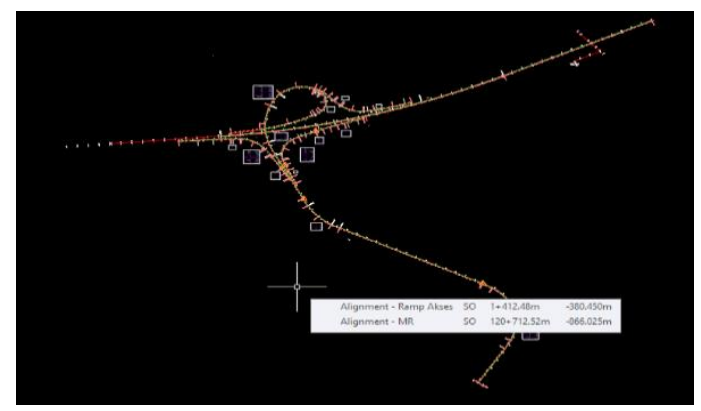

Gambar 2 Membuat Alignment Horizontal

2. Membuat superelevasi seperti yang terlihat pada Gambar 3.

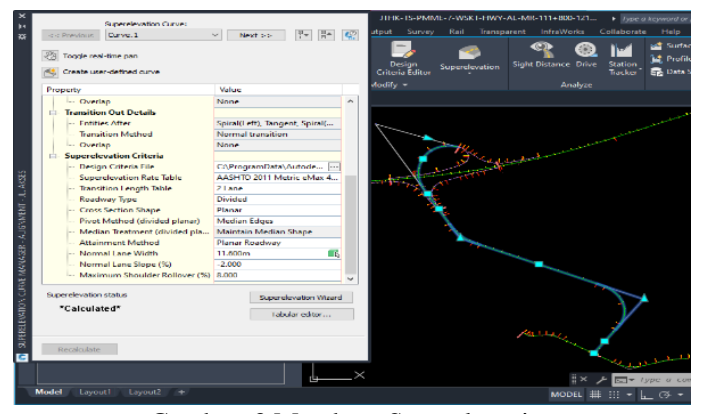

Gambar 3 Membuat Superelevasi

3. Membuat layout profile rencana (alignment vertical) seperti yang terlihat pada Gambar 4.

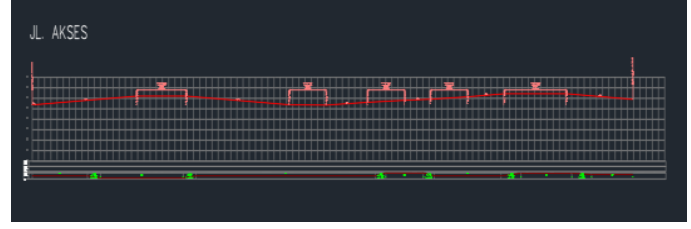

Gambar 4 Membuat Alignment Vertical

4. Membuat subassembly seperti yang terlihat pada Gambar 5.

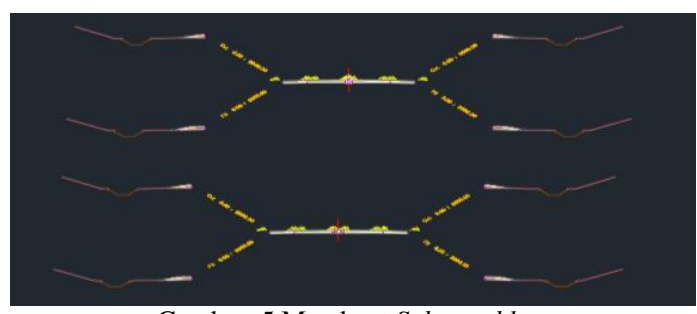

Gambar 5 Membuat Subasembly

5. Membuat corridor seperti yang terlihat Pada Gambar 6.

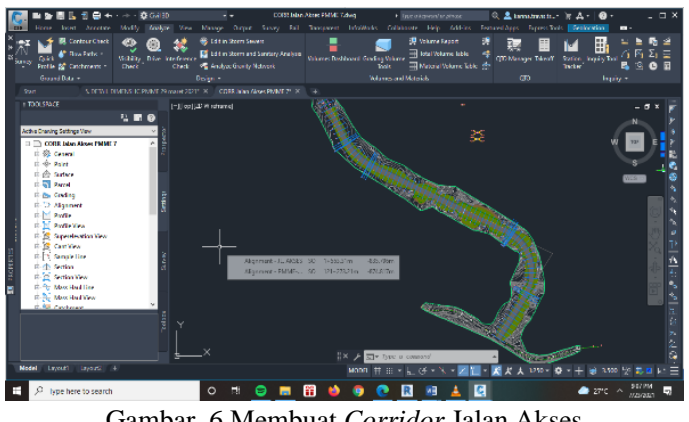

\subsection{Pemodelan 3D Struktur Overpass}

Pemodelan 3D pekerjaan struktur pada overpass akan dilakukan dengan perangkat lunak Autodesk Revit.. Pada pemodelan 3D akan dibuat berdasarkan dari dokumen RTA. Output dari pemodelan ini adalah file .RVT yang berisi seluruh data dari pemodelan yang sudah dikerjakan. Untuk merencanakan struktur overpass menggunakan Autodesk Revit terdapat tahapan-tahapan sebagai berikut:

1. Memasukkan plan struktur overpass ke Autodesk Revit seperti yang terlihat pada Gambar 7. 


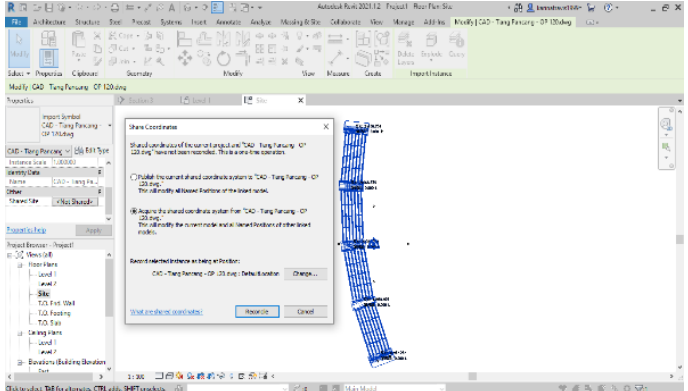

Gambar 7 Import Gambar Plan Struktur Overpass

2. Lalu buat New Family dari setiap elemen yang akan dibuat yang selanjutnya akan di plot ke dalam gambar plan. Untuk membuat elemen substructure (pondasi tiang, kepala pondasi / footing, kolom pier, kepala pier / pier head), elemen upper-structure (girder, diafragma, deck slab, pavement, dan barrier, plat injak, bearing pad), struktur tanah (granular backfill) dan utilitas railing. pilih template sesuai dengan elemen struktur yang akan dibuat. Selanjutnya placing family masing-masing elemen yang sudah dibuat ke project sesuai dengan gambar plan. Tampilan New Family seperti pada Gambar 8

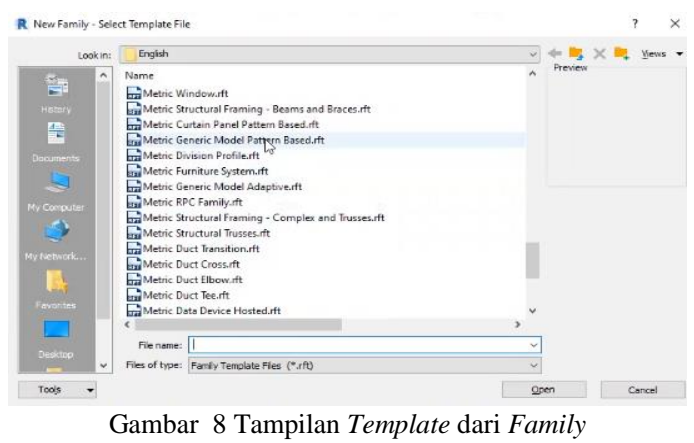

3. Membuat elemen sub-structure (pondasi tiang, kepala pondasi / footing, kolom pier, kepala pier / pier head) seperti yang terlihat pada Gambar 9.

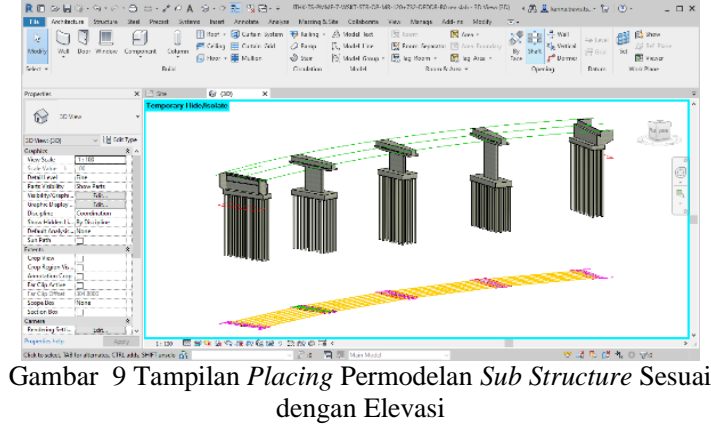

4. Membuat elemen upper-structure (girder, diafragma, deck slab, pavement, dan barrier, plat injak, bearing pad) yang terlihat pada Gambar 10.

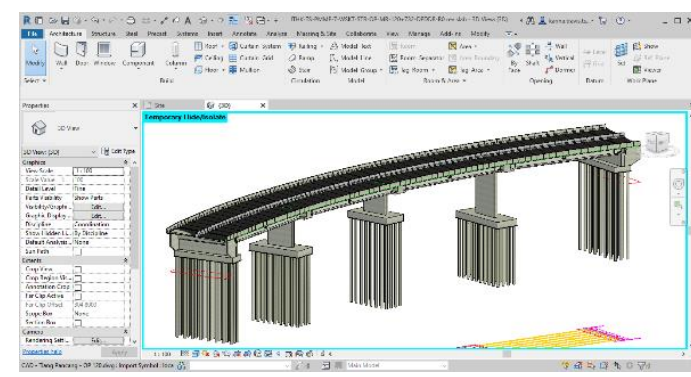

Gambar 10 Tampilan Placing Permodelan Upper Structure Sesuai dengan Elevasi

5. Membuat struktur tanah granular backfill yang terlihat pada Gambar 11.

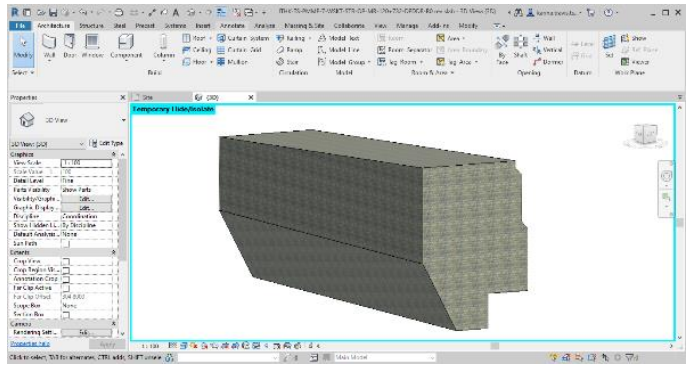

Gambar 11 Tampilan Permodelan Granular Backfill Sesuai dengan Elevasi

6. Membuat utilitas railing yang terlihat pada Gambar 12.

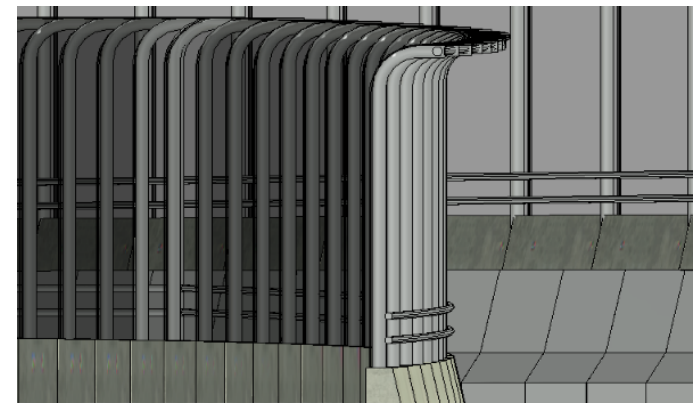

Gambar 12 Tampilan Permodelan Railing Sesuai dengan Elevasi

\subsection{Perhitungan Volume Pekerjaan Berbasis BIM}


1. 5D QTO pada at grade pada menu Generate Volume Report menggunakan Autodesk Civil 3D kon seperti yang terlihat pada Gambar 13.

\section{Material Report}

Project: C:IUsersLAPTOP 1 1AppDataLocalTTemp\Jalan Akses PMME 7_1_29982_6c0ba671.svS

Alignment: Alignment -JL. AKSES

Sample Line Group: Cross Section J1 Akses - 1

Start Sta: $0+025.000$
End Sta: $2+416.651$

\begin{tabular}{|c|c|c|c|c|}
\hline & Area Type & Area & Inc.Vol. & Cum.Vol. \\
\hline & & Sq.m. & Cu.m. & Cu.m. \\
\hline \multicolumn{5}{|l|}{ Station: $0+025.000$} \\
\hline & galian & 206.25 & 0.00 & 0.00 \\
\hline & timbunan & 23.38 & 0.00 & 0.00 \\
\hline \multicolumn{5}{|c|}{ Station: $0+050.000$} \\
\hline & galian & 386.95 & 7414.99 & 7414.99 \\
\hline & timbunan & 77.70 & 1263.52 & 1263.52 \\
\hline \multicolumn{5}{|l|}{ Station: $0+075.000$} \\
\hline & galian & 374.77 & 9521.53 & 16936.51 \\
\hline & timbunan & 136.80 & 2681.18 & 3944.70 \\
\hline \multicolumn{5}{|l|}{ Station: $0+100.000$} \\
\hline & galian & 395.85 & 9632.72 & 26569.23 \\
\hline & timbunan & 166.27 & 3788.33 & 7733.03 \\
\hline \multicolumn{5}{|l|}{ Station: $0+125.000$} \\
\hline & galian & 342.32 & 9227.08 & 35796.31 \\
\hline & timbunan & 184.76 & 4387.86 & 12120.89 \\
\hline Station: $0+150.000$ & & & & \\
\hline
\end{tabular}

\section{Material Report}

Project: C: Users\LAPTOP 1\AppDataLocal $\backslash$ Temp \alan Akses PMME 7_1_29982_6c0ba671.sv\$

Sample Line Group: Cross Section J1 Akses - 1

Start Sta: $0+025.000$
End Sta: $2+416651$

\begin{tabular}{|c|c|c|c|c|}
\hline & Area Type & Area & Inc.Vol. & Cum.Vol. \\
\hline & & Sq.m. & Cu.m. & Cu.m. \\
\hline \multicolumn{5}{|l|}{ Station: $0+025.000$} \\
\hline & rigid & 4.20 & 0.00 & 0.00 \\
\hline & LC & 1.44 & 0.00 & 0.00 \\
\hline & AGREGAT & 3.02 & 0.00 & 0.00 \\
\hline & BETON BARRIER & 0.64 & 0.00 & 0.00 \\
\hline & TANAH ROUNDING & 1.52 & 0.00 & 0.00 \\
\hline \multicolumn{5}{|l|}{ Station: $0+050.000$} \\
\hline & rigid & 4.20 & 105.00 & 105.00 \\
\hline & LC & 1.44 & 36.00 & 36.00 \\
\hline & AGREGAT & 3.02 & 75.39 & 75.39 \\
\hline & BETON BARRIER & 0.64 & 15.94 & 15.94 \\
\hline & TANAH ROUNDING & 1.52 & 38.12 & 38.12 \\
\hline \multicolumn{5}{|l|}{ Station: $0+075.000$} \\
\hline & rigid & 4.20 & 105.00 & 210.00 \\
\hline & LC & 1.44 & 36.00 & 72.00 \\
\hline & AGREGAT & 3.02 & 75.39 & 150.77 \\
\hline
\end{tabular}

Gambar 13 Tampilan Volume Report Autodesk Civil 3D

2. 5D QTO pada overpass pada menu Schedules/Quantities menggunakan Autodesk Revit seperti yang terlihat pada Gambar 14.

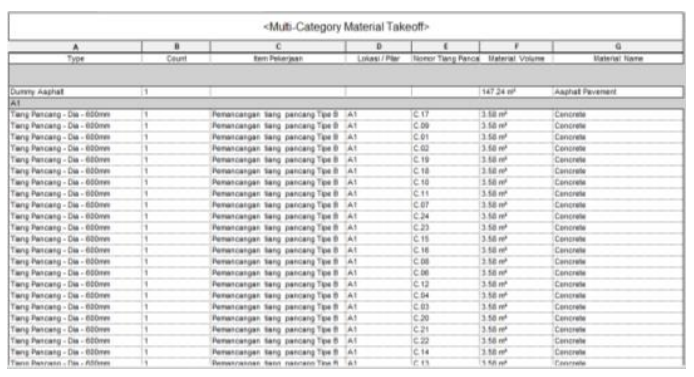

Gambar 14 Tampilan Hasil Quantity Take-off Autodesk Revit

\subsection{Perhitungan Volume Pekerjaan Berbasis CAD} Konvensional

1. Pekerjaan dalam satuan panjang $-\mathrm{m}^{1}$
Volume yang dihitung berdasarkan dari panjang konstruksi sesuai dengan gambar rencana dengan memperhatikan skala pada gambar.

2. Pekerjaan dalam satuan luas $-\mathrm{m}^{3}$

Dalam menghitung volume dengan satuan $\mathrm{m}^{3}$ yaitu dengan menghitung luas area dikalikan dengan tebal atau ketinggian dalam masing-masing objek yang akan dihitung. Luas area yang didapatkan dengan menggunakan software Autodesk Autocad menggunakan Command "LI" atau "AA" lalu di olah pada Microsoft Excel untuk membantu proses perhitungan volume. Luas area seperti yang terlihat pada Gambar 15.

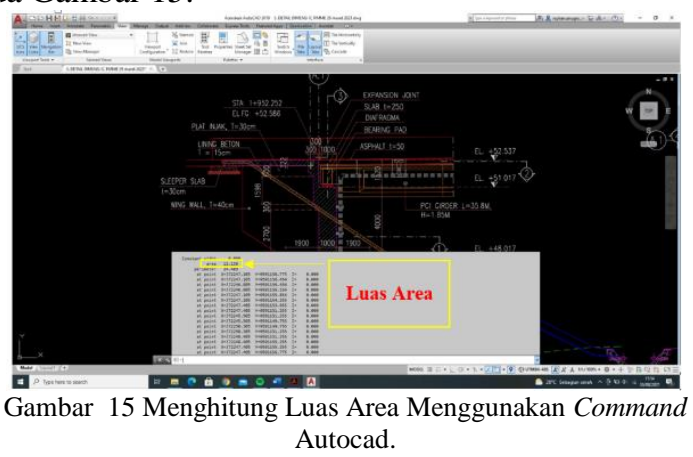

3. Pekerjaan dalam satuan $\mathrm{Kg}$

Volume yang dihitung beratnya sesuai dengan gambar rencana dengan memperhatikan skala pada gambar.

4. Pekerjaan dalam satuan - bh dihitung jumlahnya berdasarkan gambar yang ada.

\subsection{Analisa Hasil Perhitungan}

Seluruh hasil perhitungan quantity take off BIM yang menggunakan Civil 3D dan Revit yang akan dibandingkan dengan hasil perhitungan dengan CAD konvensional dan menggunakan alat bantuan Microsoft Excel. Untuk mempermudah analisa, perhitungan quantity take off tersebut diubah dalam bentuk persentase (\%) menggunakan rumus:

Persentase $=\frac{\text { volume konv-Volume BIM }}{\text { Volume BIM }} \times 100 \%$

\subsection{Analisa Kendala yang Terjadi dalam menggunakan BIM pada QTO}

Penulis dapat menemukan kendala apa saja yang terjadi saat memodelkan BIM dan melakukan analisa QTO menggunakan BIM, maka kendala tersebut dijadikan referensi untuk ditanyakan pada pakar dengan melakukan wawancara dengan satu responden yang merupakan seorang pakar BIM pada PT X dengan jabatan BIM Infrastructure Expert. Dengan adanya kendala yang berasal dari pengguna BIM dapat dijadikan masukan dan dapat diantisipasi oleh pengguna BIM lainnya. Autodesk Revit dan Autodesk Civil 3D merupakan salah satu dari beberapa software

Journal of Applied Civil Engineering and Infrastructure (JACEIT) 
yang dapat digunakan untuk pekerjaan quantity take off. Hasil kesimpulan wawancara diperoleh untuk mendukung hasil penelitian.

\section{Hasil dan Pembahasan}

\subsection{Pemodelan BIM Struktur Overpass}

Pemodelan struktur overpass menggunakan software Autodesk Revit dengan memanfaatkan gambar RTA dari Proyek Jalan Tol "X" Hasil permodelan 3D struktur overpass terdapat pada Gambar 16.

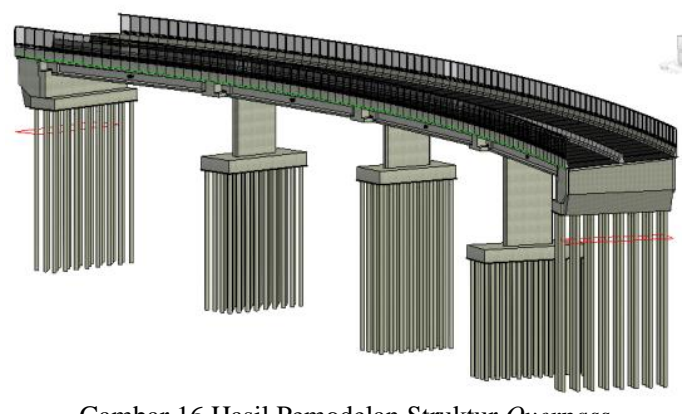

Gambar 16 Hasil Pemodelan Struktur Overpass

\subsection{Pemodelan BIM Struktur Jalan Akses/At Grade}

Pemodelan struktur Jalan Akses/At Grade menggunakan software Autodesk Civil 3D dengan memanfaatkan gambar tipikal potongan melintang jalan akses dari Proyek Jalan Tol "X". Pekerjaan jalan akses terdiri dari pekerjaan galian dan timbunan, perkerasan beton, lean concrete, lapis drainase, tanah rounding jalan dan concrete barrier. Hasil permodelan 3D Jalan Akses terdapat pada Gambar 17 dan Gambar 18.

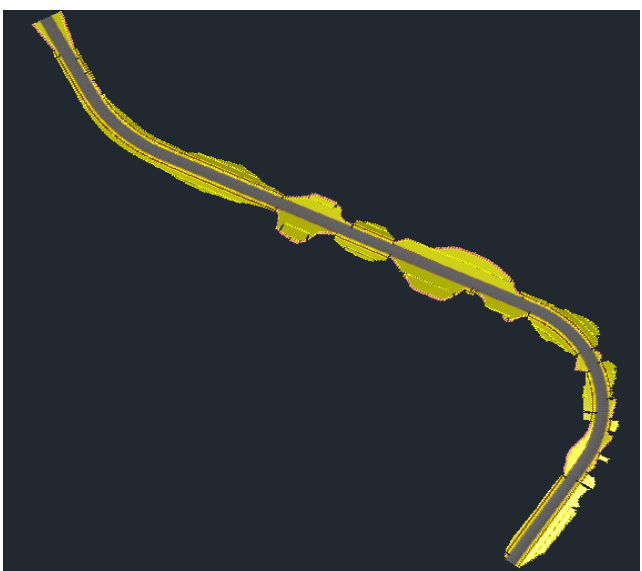

Gambar 17 Hasil Pemodelan Jalan Akses

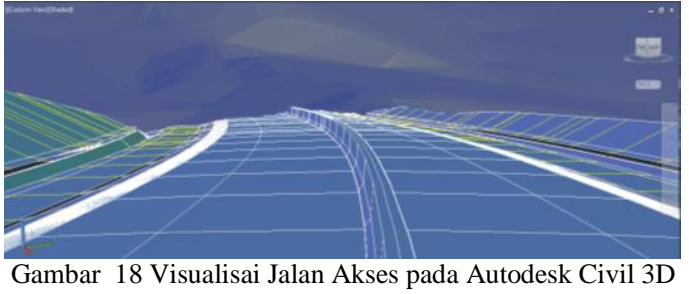

3.3. Analisa Perbandingan Hasil Perhitungan BIM dan Konvensional

Setelah pemodelan jalan akses dan struktur overpass selesai dilakukan maka dilakukan proses kalkulasi atau QTO sesuai dengan model yang sudah dibuat dan diperoleh quantity take off dari pemodelan tersebut. Selanjutnya membandingkan hasil perhitungan quantity take off menggunakan BIM yaitu hasil ekstraksi dari Autodesk Civil 3D dan Autodesk Revit dengan perhitungan quantitiy take off berbasis CAD konvensional dan Microsoft Excel yang berasal dari perhitungan sendiri. Melalui BIM hasil yang diperoleh berupa data volume beton dan luas permukaannya. Perbandingan QTO BIM dan Konvensional terdapat pada Lampiran Tabel 1.

Berikut grafik rata-rata perbandingan perhitungan tiap pekerjaan pada struktur overpass dan jalan akses gambar 4 sampai gambar 6.

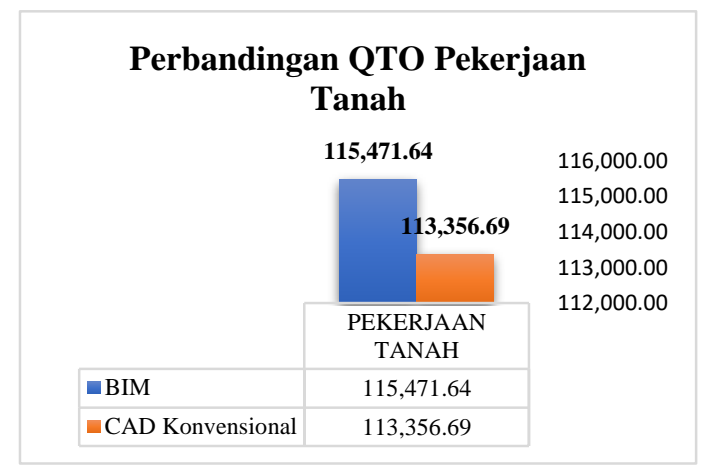

Gambar 19 Grafik Perbandingan Rata-rata QTO Pekerjaan Tanah

Dari gambar 4 didapat persentase perbedaan selisih $\pm 4,375 \%$ jika dibandingkan dengan metode perhitungan berbasis CAD konvensional.

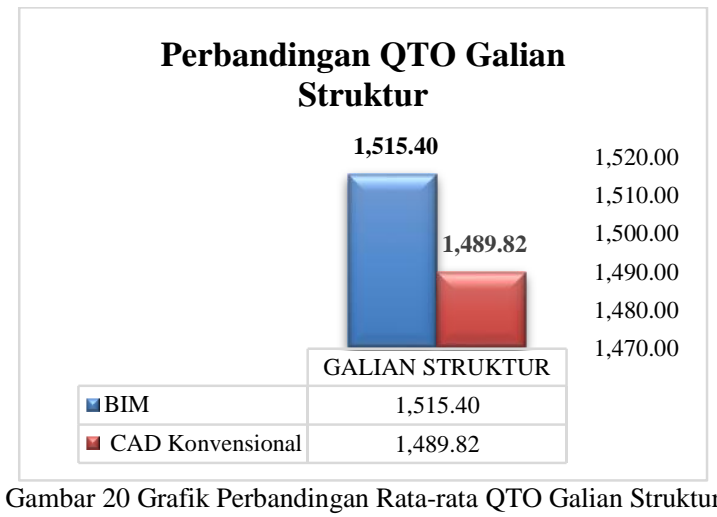

Journal of Applied Civil Engineering and Infrastructure (JACEIT) 
Dari gambar 5 didapat persentase perbedaan selisih $1,7 \%$ jika dibandingkan dengan metode perhitungan berbasis CAD konvensional.

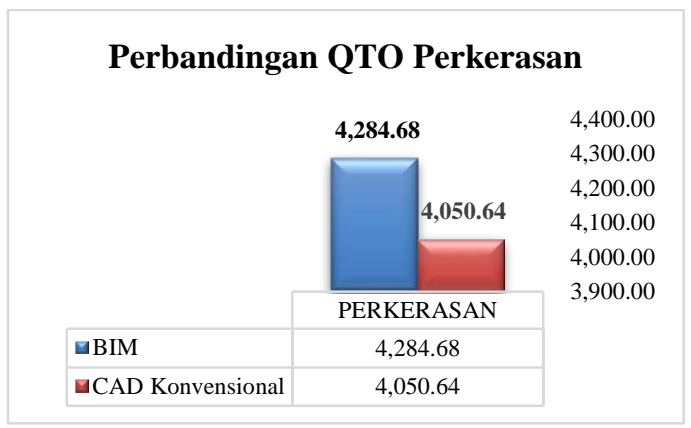

Gambar 21 Grafik Perbandingan Rata-rata QTO Perkerasan

Dari gambar 6 didapat persentase perbedaan selisih 4,4\% jika dibandingkan dengan metode perhitungan berbasis CAD konvensional.

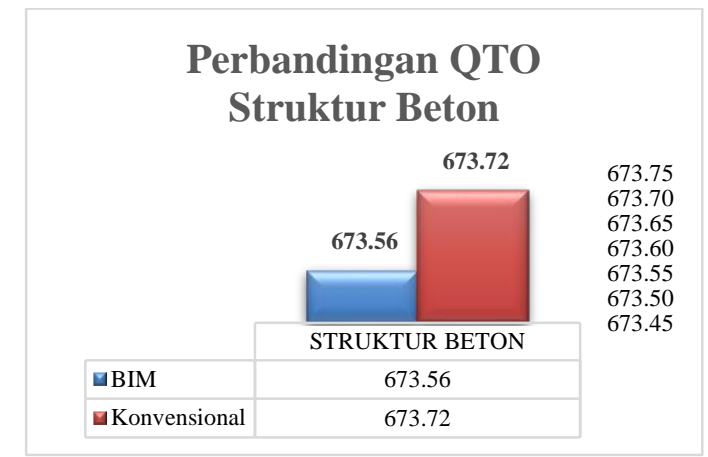

Gambar 22 Grafik Perbandingan Rata-rata QTO Struktur Beton

Dari gambar 7 didapat persentase perbedaan selisih $\pm 0,1 \%$ jika dibandingkan dengan metode perhitungan berbasis CAD konvensional.

Berdasarkan hasil rekapitulasi tabel perhitungan, terdapat beberapa hal penting yang mempengaruhi hasil perhitungan, khususnya untuk permodelan BIM 3D yaitu:

1. Karena keterbatasan waktu perhitungan dan kurangnya pemahaman tentang metode perhitungan yang akurat, perhitungan yang dilakukan secara manual menggunakan metode average end area di Microsoft Excel memliki akurasi yang lebih rendah.

2. Pada extract QTO menggunakan Autodesk Civil 3D untuk pekerjaan tanah memiliki perbedaan perhitungan $\pm 5,4 \%$, pekerjaan perkerasan perbedaan perhitungan sekitar $\pm 5,47 \%$, dan galian struktur memiliki perbedaan perhitungan $\pm 1,7 \%$ dari perhitungan manual berbasis CAD konvensional dan Microsoft Excel yang disebabkan pada metode berbasis CAD konvensional data ukur yang diambil tidak sesuai dengan keadaan dan kondisi lapangan sehingga sulit untuk mendapatkan hasil perhitungan yang akurat. Metode konvensional bisa lebih teliti jika interval jarak antar penampang irisan diperkecil , tetapi akan memakan waktu perhitungan yang lebih lama dan pada potongan memanjang gambar terkadang terdapat kesalahan proyeksi gambar. Sedangkan perhitungan menggunakan Autodesk Civil 3D menghasilkan QTO yang sangat teliti karena mendekati keadaan asli di lapangan.

3. Pada perhitungan struktur beton tidak banyak perbedaan yang signifikan karena mengacu pada gambar yang sama. Penafsiran dan asumsi yang digunakan saat melakukan perhitungan volume sama dengan yang digunakan Autodesk Revit. Perhitungan berbasis CAD konvensioal mengikuti asumsi dari Autodesk Revit yaitu dengan menghitung luas area tiap elemen struktur lalu dikalikan dengan ketebalannya. Namun untuk perhitungan manual berbasis CAD konvensional membutuhkan waktu yang cukup lama jika ingin mendapatkan hasil perhitungan yang akurat karena terdapat beda kemiringan yang mempengaruhi perhitungan.

4. Proses perhitungan berbasis BIM dan CAD konvensional dipengaruhi oleh faktor human error yang tinggi dan faktor individu yang masih ikut berperan.

5. Secara keseluruhan pengujian yang dilakukan menghasilkan selisih perbedaan perhitungan antara BIM dan konvensional dibawah $10 \%$, dan hasil penelitian ini sesuai dengan ke akuratan yang berdasarkan dari penelitian sebelumnya.

\subsection{Hasil Wawancara}

Dari hasil wawancara dengan seorang pakar BIM yang didapatkan, dapat disimpulkan kendala dalam penerapan BIM yaitu:

1. Kemampuan dari pihak yang akan menggunakan BIM saat akan melakukan permodelan, apabila model yang dikerjakan tidak sesuai maka akan memberikan hasil perhitungan yang salah.

2. Pada proses QTO sering terjadi glitch pada pekerjaan galian dan timbunan yang mengandalkan data ukur, jika kesalahan dalam pengambilan data ukur maka pemodelan akan salah. Kendala saat proses calculate QTO terkadang terdapat model yang menduplikasi jika pada saat memodelkan kurang teliti. Dan jika saat memodelkan tidak memasukkan informasi dengan lengkap, maka akan saat export quantity tidak bisa mendapatkan informasi yang dibutuhkan.

3. Waktu pemodelan yang cukup lama dalam mengoreksi model dengan data yang salah/tidak sesuai dengan desain rencana dan kesalahan pendetailan gambar yang diberikan oleh konsultan juga merupakan salah satu kendala saat memodelkan BIM. Dibutuhkan ketelitian yang sangat tinggi dalam modelling agar mendapatkan hasil yang didapatkan sama dengan aktual. Tingkat keakuratan dalam pekerjaan QTO

Journal of Applied Civil Engineering and Infrastructure (JACEIT) 
dipengaruhi oleh tingkat kedetailan dari BIM disebabkan kurangnya ketelitian, diperlukan waktu Model.

yang lama dan ketelitian yang tinggi untuk

4. Penggunaan software yang sulit yang menghasilkan perhitungan QTO yang akurat, tingkat membutuhkan kualifikasi keahlian yang tinggi, keakuratan dalam pekerjaan QTO dipengaruhi oleh serta membutuhkan spesifikasi perangkat yang tingkat kedetailan dari BIM Model tersebut, output tinggi untuk penggunaannya.

yang dikeluarkan BIM perlu untuk dikeluarkan lagi.

5. Lisensi software yang mahal, tetapi hasil yang didapatkan dari penggunaan BIM dapat Daftar Rujukan memberikan kefisiensian yang cukup besar khususnya untuk perhitungan QTO dan juga dapat memberikan keuntungan dari segi biaya, mutu, waktu, visualisasi, dll.

6. Output yang dikeluarkan oleh BIM masih berantakan dan perlu diolah lagi agar sesuai dengan format yang ada.

7. Semakin rumit permodelan maka akan semakin sulit BIM memproses data pada model tersebut. Hal ini mempengaruhi waktu dari pengerjaan permodelan sampai dengan hasil final. Jika pemodelan BIM tidak dimodelkan dengan benar maka akan memberikan hasil perhitungan volume yang salah karena tingkat keakuratan dalam pekerjaan QTO dipengaruhi oleh tingkat kedetailan dari BIM Model tersebut. Dibutuhkan pemahaman yang tinggi kepada seluruh BIM engineer tentang jalan tol.

\section{Kesimpulan}

Autodesk Revit dan Autodesk Civil 3D dapat melakukan permodelan elemen-elemen struktur dengan baik dan dapat mempermudah perhitungan QTO karena dapat menghitung secara otomatis setelah pemodelan BIM 3D dibuat. Dengan permodelan yang berbentuk 3D memudahkan banyak pihak untuk menganalisa dan mengkoreksi apabila terjadi perbedaan volume baik dari konsultan maupun owner, sehingga mencegah terjadinya perselisihan. Semakin rumit permodelan maka akan semakin sulit BIM memproses data pada model tersebut. Hal ini mempengaruhi waktu dari pengerjaan permodelan sampai dengan hasil final.

Pada item pekerjaan struktur overpass yang dihitung sebanyak 20 item. Pada item pekerjaan jalan akses yang dihitung sebanyak 7 item. Ditemukan perbandingan hasil perhitungan quantity take off dengan menggunakan BIM dan konvensional. Persentase perbedaan perhitungan yang didapatkan yaitu pada pekerjaan tanah selisih $\pm 4,375 \%$, Galian struktur selisih $\pm 1,7 \%$, Perkerasan selisih $\pm 4,4 \%$, struktur beton selisih $\pm 0,1 \%$, dan pekerjaan lain-lain $0 \%$ jika dibandingkan dengan metode perhitungan konvensional. Hal ini disebabkan kurangnya ketelitian dalam melakukan perhitungan volume berbasis CAD konvensional, sehingga volume yang dihasilkan tidak akurat.

[1] M. S. Alshabab, U. Al-baath, and A. Revit, "BIM-Based Quantity Takeoff. Construction of Unique Buildings and Structures," vol. 4, no. 55, pp. 124-134, 2017.

[2] M. H. U. Akbar, "Comparison Between the BOQ of Conventional and BIM Method on BPJS Building in Central Jakarta," Log. J. Ranc. Bangun dan Teknol., vol. 21, no. 1, pp. 31-30, 2021, doi: 10.31940/logic.v21i1.2260.

[3] A. Monteiro and J. Poças Martins, "A survey on modeling guidelines for quantity takeoff-oriented BIM-based design," Autom. Constr., vol. 35, pp. 238-253, 2013.

[4] H. S. J. and K. A. T. O. R. Gemunu Kulasekara, "Comparative Effectiveness Of Quantity Surveying In A Building Information Modelling Implementation," Second World Constr. Symp. 2013 Socio-Economic Sustain. Constr., vol. 5, no. 14-15 June, pp. 101-107, 2013.

[5] O. P. S. Ardianto, T. A. Kristianto, C. A. Budianto, A. A. Rucitra, and A. Wardoyo, "Evaluasi Media Presentasi Perancangan Interior Rumah Air Surabaya Berbasis Virtual Tour sebagai Usaha Penerapan Building Information Modelling pada Perancangan Interior," J. Desain Inter., vol. 4, no. 1, p. 11, 2019.

[6] R. Raflis, B. E. Yuwono, and R. Rayshanda, "Manfaat Penggunaan Building Information Modelling (Bim) Pada Proyek Konstruksi Sebagai Media Komunikasi Stakeholders," Indones. J. Constr. Eng. Sustain. Dev., vol. 1, no. 2, p. 62, 2019.

[7] SURAT EDARAN Nomor: 11/SE/Db/2021, "PENERAPAN BUILDING INFORMATION MODELLING PADA PERENCANAAN TEKNIS, KONSTRUKSI DAN PEMELIHARAAN JALAN DAN JEMBATAN DI DIREKTORAT JENDERAL BINA MARGA," no. 20, 2013.

[8] H. Berlian, Cinthia Ayu; Adhi, Randy Putranto; Nugroho, "Perbandingan Evisiensi Waktu,Biaya dan Sumber Daya Manusia Antara Metode BIM dan Konvensional (Studi kasus :Perencanaan Gedung 20 Lantai)," J. Karya Tek. Sipil, vol. 5, no. 2, pp. 220-229, 2016.

[9] H. P. Rizal Maulana Rizqy, Nunung Martina, "Perbandingan Metode Konvensional Dengan Bim Terhadap Efisiensi Biaya, Mutu, Waktu," vol. 3, no. 1, pp. 15-24, 2021.

[10]A. N. Hasan and S. M. Rasheed, "The Benefits of and Challenges to Implement 5D BIM in Construction Industry," Civ. Eng. J., vol. 5, no. 2, p. 412, 2019.

[11]R. Stanley and D. Thurnell, "The benefits of, and barriers to, implementation of 5D BIM for quantity surveying in New Zealand," Australas. J. Constr. Econ. Build., vol. 14, no. 1, pp. 105-117, 2014.

[12]Y. Marizan, "Studi Literatur Tentang Penggunaan Software Autodesk Revit Studi Kasus Perencanaan Puskesmas Sukajadi Kota Prabumulih," J. Ilm. Bering's, vol. 06, no. 01, pp. 15-26, 2019.

[13]D. Laorent, P. Nugraha, and J. Budiman, "Analisa Quantity Take-Off Dengan Menggunakan Autodesk Revit," Dimens. Utama Tek. Sipil, vol. 6, no. 1, pp. 1-8, 2019.

[14] Y. Arayici, P. Coates, L. Koskela, M. Kagioglou, C. Usher, and K. O'Reilly, "Technology adoption in the BIM implementation for lean architectural practice," Autom. Constr., vol. 20, no. 2, pp. 189-195, 2011, [Online].

[15]K. Nyberg, "Possibilities with BIM in relation to cost estimation and scheduling," BIM-cost Estim., 2014.

[16]D. Olsen and J. M. Taylor, "Quantity Take-Off Using Building Information Modeling (BIM), and Its Limiting Factors," Procedia Eng., vol. 196, pp. 1098-1105, 2017.

Kendala yang ditemukan dalam penerapan BIM yaitu [17]Lu, W., Pexng, Y., Shen, Q., \& Li, H. "Generic model for kurangnya pemahaman, kurangnya kompatibilitas perangkat lunak, terdapat glitch saat extract QTO yang measuring benefits of BIM as a learning tool in construction tasks. Journal of Construction Engineering and Management." 139(2), 195-203. 2012

Journal of Applied Civil Engineering and Infrastructure (JACEIT) 
Tabel 1 Perbedaan Perhitungan QTO Manual dan BIM

\begin{tabular}{|c|c|c|c|c|c|}
\hline NO & URAIAN PEKERJAAN & SAT. & VOL. MANUAL & VOL. BIM & $\begin{array}{c}\text { DEV. } \\
(\%)\end{array}$ \\
\hline DIV.4 & PEKERJAAN TANAH & & & & \\
\hline $4.03(1) \mathrm{a}$ & $\begin{array}{l}\text { Galian Biasa untuk Timbunan max } 5 \\
\mathrm{~km}\end{array}$ & $\mathrm{M}^{3}$ & 281594 & 283447 & $0,7 \%$ \\
\hline $4.05(1) \mathrm{a}$ & $\begin{array}{l}\text { Common Borrow Material } 0 \text { - } 5 \mathrm{~km} \\
\text { (Jalan Akses) }\end{array}$ & $M^{3}$ & 169533 & 175961 & $3,7 \%$ \\
\hline $4.05(1) \mathrm{a}$ & $\begin{array}{l}\text { Common Borrow Material } 0 \text { - } 5 \mathrm{~km} \\
\text { (Khusus Overpass) }\end{array}$ & $\mathrm{M}^{3}$ & 1427,33 & 1617,59 & $11,8 \%$ \\
\hline 4.09 & $\begin{array}{l}\text { Urugan Material Berbutir (Granular } \\
\text { Backfill) (struktur Overpass) }\end{array}$ & $\mathrm{M}^{3}$ & 872,45 & 860,97 & $1,3 \%$ \\
\hline DIV.5 & GALIAN STRUKTUR & & & & \\
\hline $5.01(1)$ & Galian Struktur kedalaman $>0-2 \mathrm{~m}$ & $\mathrm{M}^{3}$ & 1489,82 & 1515,4 & $1,7 \%$ \\
\hline DIV.9 & PERKERASAN & & & & \\
\hline $9.07(3)$ & $\begin{array}{l}\text { Asphalt Concrete Wearing Course } \\
\text { (Struktur OP) }\end{array}$ & $\mathbf{M}^{3}$ & 147,34 & 147,24 & $0,1 \%$ \\
\hline $9.08(1)$ & $\begin{array}{l}\text { Perkerasan Beton (Jalan Akses) STA } \\
0+000-1+775.00\end{array}$ & $\mathrm{M}^{3}$ & 8104,26 & 8580 & $5,5 \%$ \\
\hline $9.09(1)$ & $\begin{array}{l}\text { Lean Concrete (Jalan Akses) STA } \\
0+000-1+775.00\end{array}$ & $\mathrm{M}^{3}$ & 2768,96 & 2931,5 & $5,5 \%$ \\
\hline \multirow[t]{2}{*}{9.10} & $\begin{array}{l}\text { Lapis Drainase(Jalan Akses) STA } \\
0+000-1+775.00\end{array}$ & $\mathrm{M}^{3}$ & 5813,72 & 6152,4 & $5,5 \%$ \\
\hline & $\begin{array}{l}\text { Tanah Rounding (Jalan Akses) STA } \\
0+000-1+775.00\end{array}$ & $M^{3}$ & 3418,91 & 3612,24 & $5,4 \%$ \\
\hline DIV. 10 & STRUKTUR BETON & & & & \\
\hline $10.01(4 a)$ & $\begin{array}{l}\text { Beton Struktur Kelas B-1-1a (Lantai } \\
\text { Beton Bertulang dari Gelagar Beton } \\
\text { Pratekan U/I) }\end{array}$ & $\mathrm{M}^{3}$ & 719,43 & 722,2 & $0,4 \%$ \\
\hline $10.01(5)$ & $\begin{array}{l}\text { Beton Struktur Kelas B-1-2 } \\
\text { (Diafragma dari Gelagar Beton } \\
\text { Pratekan U/I) }\end{array}$ & $\mathrm{M}^{3}$ & 93,60 & 92,64 & $1,0 \%$ \\
\hline $10.01(5 a)$ & $\begin{array}{l}\text { Beton Struktur KelasB-1-3 (Kepala } \\
\text { Pier Beton Bertulang) }\end{array}$ & $\mathrm{M}^{3}$ & 475,84 & 475,51 & $0,1 \%$ \\
\hline $10.01(7 f)$ & $\begin{array}{l}\text { Beton Struktur KelasB-1-4f (Kolom } \\
\text { Beton Bertulang dari Pier) }\end{array}$ & $\mathbf{M}^{3}$ & 275,13 & 275,13 & $0,0 \%$ \\
\hline $10.01(9)$ & $\begin{array}{l}\text { Beton Struktur Kelas B-1-6 (Beton } \\
\text { Penghalang/ Barrier) }\end{array}$ & $\mathbf{M}^{3}$ & 255,91 & 254,23 & $0,7 \%$ \\
\hline Item Baru & $\begin{array}{l}\text { Beton Struktur Kelas B-1 (Abutments, } \\
\text { Telapak Pier, Dinding Penahan } \\
\text { Tanah, Pelat Injak) }\end{array}$ & $\mathrm{M}^{3}$ & 1060,26 & 1058,2 & $0,2 \%$ \\
\hline $10.01(14)$ & $\begin{array}{l}\text { Beton Struktur Kelas E } \\
\text { Gelagar PC-I CTC } 2.4 \text { m bentang }\end{array}$ & $\mathrm{M}^{3}$ & 50,27 & 50,27 & $0,0 \%$ \\
\hline $10.03(15 a)$ & $\begin{array}{l}\text { nominal } 35,8 \mathrm{~m} \text { to } 32.00 \mathrm{~m}, \mathrm{H}=1.85 \mathrm{~m} \text {, } \\
\text { penyediaan }\end{array}$ & $\mathrm{Bh}$ & 28 & 28 & $0,0 \%$ \\
\hline $10.03(15 b)$ & $\begin{array}{l}\text { Gelagar PC-I CTC } 2.4 \mathrm{~m} \text { bentang } \\
\text { nominal } 35,8 \mathrm{~m} \text { to } 32.00 \mathrm{~m}, \mathrm{H}=1.85 \mathrm{~m} \text {, } \\
\text { pemasangan }\end{array}$ & $\mathrm{Bh}$ & 28 & 28 & $0,0 \%$ \\
\hline $10.05(1)$ & $\begin{array}{l}\text { Penyediaan tiang pancang Tipe } \mathrm{B} \\
\text { beton bulat pretensioned, dia. } 60 \mathrm{~cm}\end{array}$ & M1 & 3164 & 3164 & $0,0 \%$ \\
\hline $10.05(2)$ & $\begin{array}{l}\text { Pemancangan tiang pancang Tipe } \mathrm{B} \\
\text { beton bulat pretensioned,dia. } 60 \mathrm{~cm}\end{array}$ & M1 & 3164 & 3164 & $0,0 \%$ \\
\hline $10.10(1 a)$ & $\begin{array}{l}\text { Sambungan Ekspansi Strip Seal Joint } \\
\text { Tipe heavy duty }(\leq 80 \mathrm{~mm})\end{array}$ & M1 & 61,6 & 61,6 & $0,0 \%$ \\
\hline $10.11(26)$ & Anchor Bar dengan Perlengkapannya & KG & 2915,75 & 2915,75 & $0,0 \%$ \\
\hline Item Baru & $\begin{array}{l}\text { Elastomeric Bearing Pad 400x } 500 \times 45 \\
\text { (fix) }\end{array}$ & $\mathrm{Bh}$ & 28 & 28 & $0,0 \%$ \\
\hline Item Baru & $\begin{array}{l}\text { Elastomeric Bearing Pad 400x } 500 \times 45 \\
\text { (move) }\end{array}$ & $\mathrm{Bh}$ & 28 & 28 & $0,0 \%$ \\
\hline DIV. 12 & PEKERJAAN LAIN-LAIN & & & & \\
\hline $12.15(2)$ & $\begin{array}{l}\text { Concrete Barrier, tipe - B (Jalan } \\
\text { Akses) }\end{array}$ & M1 & 1800 & 1800 & $0,0 \%$ \\
\hline
\end{tabular}

Sumber: Olahan Penulis 